Int. J. Dev. Biol. 55: 243-247 (2011)

doi: $10.1387 / \mathrm{ijdb} .103281 \mathrm{~mm}$

\title{
The biopolitics of frozen embryos
}

\author{
MANUELA MONTI ${ }^{*}, 1$ and CARLO A. REDI ${ }^{2}$ \\ ${ }^{1}$ Scientific Unit, San Matteo Foundation for Research, Hospitalization and Health Care and \\ ${ }^{2}$ Developmental Biology Unit, Department of Animal Biology, University of Pavia, Pavia, Italy
}

\begin{abstract}
The unresolved debate about frozen embryos has left open the discussion on "what to do with them". There are only three ways to deal with frozen embryos: 1) to leave them frozen indefinitely; 2) to defrost and discard them and 3) to use them for research. In this paper, we suggest that the application of current scientific knowledge, instead of inappropriately referring to ethical principles or to the concept of person, could help with the decision about what to do with hundreds of thousands of frozen embryos, thus bringing the sensitive debate on bioethical issues to shared practical solutions. We face a new individual only when a new functional copy of his genome is formed. In both natural and artificial animal and plant reproduction, this principle applies. This status occurs in humans at the 4-8 cell stage. Acknowledgement of this factual datum would allow advocates of all religious and ideological beliefs to defend their principles and to realign their positions to a setting within the boundaries of current scientific knowledge.
\end{abstract}

KEY WORDS: biopolitics, frozen embryo, functional genome, human being, scientific citizenship, stem cell

\section{Necessary preliminary remarks: political decision makers need a biological background}

Knowledge brings cultural and medical benefits to society and is, therefore, now considered the engine for social and economic development of advanced countries. This concept is indisputable, since it has been consolidated over centuries of history, particularly in Europe. Through the ages, philosophical thought, artistic creation and scientific innovation allowed social development and cultural progress, which are unique to our species. After the century of chemistry (1800s) and physics (1900s) we entered the century of biology in which both culture and economics are based on the advancement of knowledge in the life sciences. The most recent progress in this field determines the wide impact of all forms of biotechnology in politics, human rights and, more in general, on aspects of daily life. The real political themes have at the present time, a bio-political nature being often concentrated on topics related to the beginning and the end of life, the environment and the production of food. All these bio-political topics inevitably prompt discussion about justice and between the parties which often have conflicting interests. Scientific information should be made available to everybody, allowing citizens to develop their own ideas and make prejudice-free decisions about topics important for their own life. The gained knowledge of the most recent progress in research must be considered as an integral part of our culture. This is a discipline that requires patience and time in order to grasp concepts that are essential for a knowledgeable judgment of practical applications.

Only humanistic culture can shed light on these processes, and therefore any good scientist should possess this kind of culture. On the other hand, any good scholar in humanistic disciplines not only needs to adopt the scientific method - which is universal - but also needs to be acquainted with scientific knowledge.

Among the several hot topics in life sciences, the wide range of problems raised by stem cells (SC) and frozen embryos (for a review see Green, 2008) play a crucial role and needs, as modus ponens, a scientific approach for a fruitful discussion.

\section{Embryos and personhood}

Internationally, with more or less emphasis, political decisionmakers tend to discuss the nature of the embryo without paying attention to the knowledge and opinions of scientists. There is reluctance in opening the doors of free scientific information and there are still constraints that prevent citizens from expressing themselves, freely, even on those possible applications that are deemed lawful. The general public is manipulated with poor information and alarmism about what the "mad" scientists would like to do (see the last European report: Europeans and Biotechnology in

Abbreviations used in this paper: GM, genetic modification; iPS, induced pluripotent stem cell; IVF, in vitro fertilization; SC, stem cell.

\footnotetext{
*Address correspondence to: Manuela Monti. Scientific Unit, San Matteo Foundation for Research, Hospitalization and Health Care, Viale Camillo Golgi, 19 - 27100 Pavia, Italy. Fax: +39-038-298-6270. e-mail: m.monti@smatteo.pv.it
}

Accepted: 23 May 2011. Final, author-corrected PDF published online: 10 June 2011

ISSN: Online 1696-3547, Print 0214-6282

(C) 2011 UBC Press

Printed in Spain 
2010. Winds of change?; http://ec.europa.eu/). The most dramatic example of this is how some countries still fail to deal with cryopreserved embryos derived from in vitro fertilization, even though a large body of careful empirical analysis from the Social Studies of Science has unequivocally shown that very stable bioethical settlements can be reached thanks to the intimate co-production of both an epistemological and a social order (Mulkay, 1997; Jasanoff, 2005). Nowadays, we think that additional considerations arising from new scientific evidence can enrich the embryo debate on bioethical issues with new practical solutions. In other words, we suggest the application of updated scientific knowledge (at both cellular and molecular levels) about how the embryo develops, to advance the debate on the status of frozen embryos, trying to solve the normative questions of what to do with them.

There are three ways to deal with frozen embryos (Fig.1. adoption is excluded from the list because it is impractical and unrealistic: as an example, in Italy only two or three embryos a year are implanted into adoptive mothers):

1) to leave them frozen indefinitely;

2) to defrost and discard them, thus accelerating their deaths;

3) to use them for research into cell differentiation. This would arguably mean "keeping the embryos alive", albeit at the cellular level, providing mankind with important scientific knowledge about how to use cells in regenerative cell therapies. In other words, in an extended way, the embryo's cells would be spread to other living individuals.

Our proposal should allow to look beyond ideological, religious and ethical views and to ensure (it is the third option above) the embryo's life, whose meaning is shifted from the level of organism (even if potential) to the level of cells. In our view the decision should be based on what to do instead of considering what they are, trying to unlock the opposite positions whereby the use of frozen embryos is a form of respect (Gibson, 2007) or is something

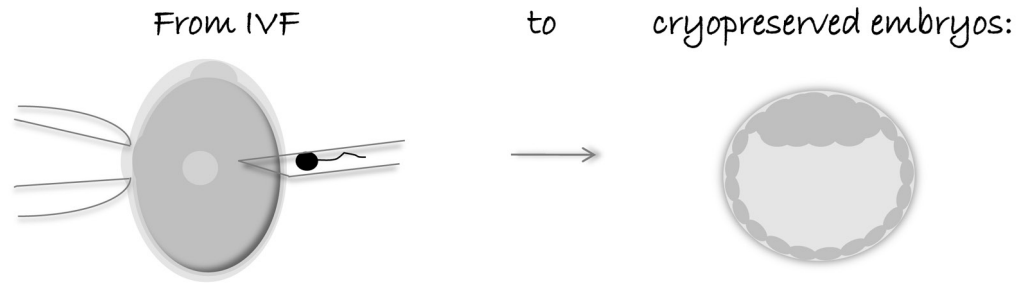

Freeze them, indefinitely
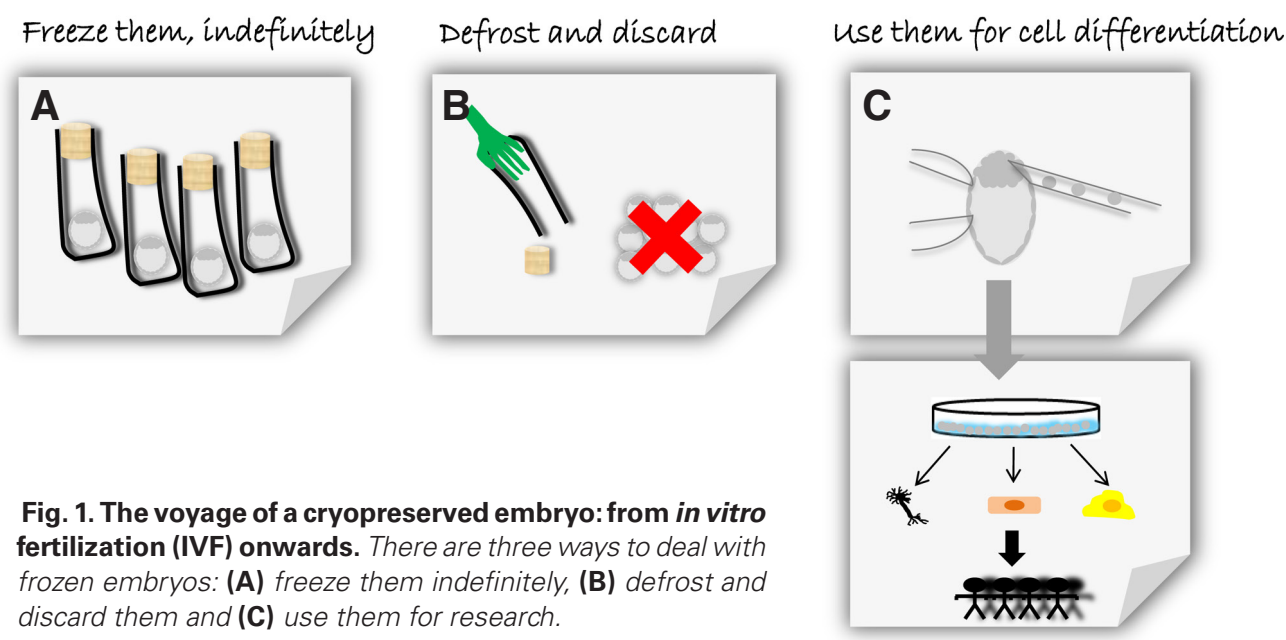

Fig. 1. The voyage of a cryopreserved embryo: from in vitro fertilization (IVF) onwards. There are three ways to deal with frozen embryos: (A) freeze them indefinitely, (B) defrost and discard them and (C) use them for research. inadmissible (following the 2008 Instruction Dignitas personae of the Congregation for the Doctrine of the Faith which can be downloaded from www.vatican.va). Particularly, this last position is apparently calling for a solution, as stated (...there seems to be...) in paragraph 1.1: "The dignity of a person must be recognized in every human being from conception to natural death" and in paragraph 19.4: "All things considered, it needs to be recognized that the thousands of abandoned embryos represent a situation of injustice which in fact cannot be resolved. ....... there seems to be no morally licit solution regarding the human destiny of the thousands and thousands of 'frozen' embryos which are and remain the subjects of essential rights and should therefore be protected by law as human persons". We suggest this to be the action of letting the embryo live at the cellular level. Of course, any kind of action assumes a definition of involved items. What we mean is that for some conditions, regardless of our personal definition of what an embryo is, action is inescapable. The main argument against the third option is the destruction of embryos, assumed such destruction is against morals or, at least, questionable action. The same argument may be used against the second option. The first option only apparently preserves the life of the embryos, as it is synonymous with death, albeit slow. It has to be considered that under certain circumstances (the abandonment by parents, long term freezing, the uncertainty of the safety of implantation of "old" embryos, which were frozen according to unsafe procedures, etc) and after a certain time (to be prudentially established), there is no chance for the embryo to develop its potentiality to become a foetus and a baby. Under these circumstances, those who believe that the frozen embryo is a person should accept, without renouncing their beliefs, that, in brief, leaving embryos frozen indefinitely is not, despite its appearance, an inaction but an action: the action of killing them slowly through omission. If this is true, as we assume, we are full circle to action, whatever the personal ontological idea of what an embryo is. These embryos exist and demand a better fate than being kept frozen indefinitely or being discarded: now that they have been created, they petition us to play a part in the matter-energy process that we call life. It is important to remember once again, how the application of current, updated scientific knowledge could facilitate decisions about what to do with hundreds of thousands of frozen embryos, instead of inappropriately referring to ethical principles or to the concept of person (George and Lee, 2009). This concept does not belong to biology or to factual science, and it is only valid in philosophy, law and theology: the character mask in Greco-Roman theatre, and the Holy Trinity and Christ as a person. Many religions consider animals and hurricanes to be people with souls, just like human beings. One suggestion might be to find an operational definition of ethics, the theory and practice of the conduct aimed at finding happiness through being good. Aristotle thought 
that happiness and good were virtues, whereas Kant thought they meant having the autonomy to behave according to universal laws. But it is not easy to determine the factual nature of being good. Indeed, it is clear that the alleged ethical consensus of humanity continues to be a beguiling hypothesis: man's exploitation of man, the just war and human history in its entirety, suggest that the hypothesis is probably false. Ethics are determined by religion and ideology. Religion entails adhesion to a view of the world in which life is constrained (relegated) to the notion of fundamental choice, to the extent that you would even give your life in support of this choice. Ideology is a vision and assessment of the world marked by social transcendence (political ethics in Aristotle). Therefore, we cannot expect a Hindu, a Christian and a dialectical materialist to follow the same ethics. Today's complex world is based on scientific advances in knowledge (economy, medicine, food production, etc.) thus even laypeople need to know the basic principle of the ongoing advances in scientific knowledge to responsibly live in modern societies, since the basic element of ethics is responsible conduct (conscious and voluntary) for making a choice. To acquire the conceptual instruments needed to assess technical applications (an integral part of our culture) requires patient dedication that is the only way to assist responsible, decision-making choices. Today, in the age of knowledge-based societies, those instruments are necessary, especially for society's leaders, such as political decision makers, magistrates and journalists. The generation gap that affects attitudes towards the technical reproducibility of particular phase of embryo development is once again paradigmatic and for this reason, it is hindering all SC research, notably in Italy, Austria, Germany and Ireland, only to name some Europeans countries.

\section{The new copy of a functional genome and the human being}

As already stated, this hindrance certainly derives from the refusal of a scientific approach to the problem. It is clear that different opinions about the embryo derive from disagreements in defining the exact moment (during the developmental process) when a cell becomes a new "individual". In this regard, there is an interesting flowering of papers (Devolder and Harris, 2005; Devolder, 2009; Testa et al., 2007), but certainly not an unambiguous idea. Since a new human being (composed of about one million billion cells $\left(10^{15}\right)$ ) originates from a developmental process programmed in the first copy of the new individual's DNA, the zygote's genome, we would like to suggest the following proposal: we are facing a new individual only when a new functional genome is formed. This statement has been ascertained by biological knowledge that allows us to clearly establish the beginning of the developmental process leading to an individual with the formation of the first new functional copy of his genome (Puschendorf et al., 2008; Wong et al., 2010): new because it is something which has never existed before in terms of its allele composition due to the genetic recombination brought about by sexual reproduction in the maternal and paternal genomes; functional because till the moment of the 4 to 8 cell transition (in humans), the maternal and paternal half-genomes in the blastomere nuclei are not yet fully integrated, mixed and expressing their gene contents. Untill that moment, zygote-embryo survival takes advantage of all the maternal factors (carbohydrates, lipids, proteins, mRNA, mitochondria, etc) embedded in the oocyte cytoplasm during the folliculogenesis period. As is well known, the paternal contribution is limited to half the genome. Genetics, epigenetics and molecular morphologies supports the "new functional copy of the genome" view: from the re-evaluation of the classical paper of McGaughey and Chang (1969) showing that the male and female pronuclei proceed through G1, S-phase and G2 of the first mitosis as separate pronuclei, to more recent papers (Braude et al., 1988; Zimmermann and Schultz, 1994; Mayer et al., 2000; Fulka et al., 2004; Puschendorf et al., 2008; Zernicka-Goetz et al., 2009; Chen et al., 2010; Wong et al., 2010; Plachta et al., 2011; Wossidlo et al., 2011; Zernicka-Goetz, 2011) stressing that gene expression of the new genome switches on at the 4-8 blastomere transition. Very recently, Plachta et al., (2011) demonstrated that the pluripotency mastergene Oct4 shows two distinct kinetic behaviors that predicts cell fate during the pre-compaction stages at the 4 - 8 cell transition (and not before!). All forms of animal and plant reproduction, both natural (fertilization and parthenogenesis) and artificial (assisted reproduction and cloning), share this principle; the principle accordingly assumes a universal validity that shelters it from all doubt whatsoever, and diffuses all other propositions regarding the ontogenetic origin of a living being (Findlay et al., 2007; Sagan and Singer, 2007; Downs, 2008; George and Lee, 2009). In mammals, this originating moment does not coincide with the appearance of the unicellular embryo, the zygote, but it varies according to different species, for example: at the two cells stage in mice (Mayer et al., 2000) and at the four/eight cells stage in humans where the regulatory mechanisms essential for the cell fate decisions in embryogenesis are just maternal-genome determined up to the four/eight-cell embryo stage (Braude et al., 1988; Fulka et al., 2004; Chen et al., 2010). Acknowledgement of this factual datum would allow advocates of all religious and ideological standpoints both to defend their principles and to realign their positions to a setting within the boundaries of current scientific knowledge. We suggest that this new view should be evaluated in the current embryo debate by stressing that no other views (either based on religious prejudices or ideological beliefs or gradualist convictions) can claim such a universal scientific attribute in its setting up. Thus, the new functional copy of the genome view is much more sheltered from inconsistencies and is catching off guard all other views. At least two positions are misleading (i.e., specious, faulty; Gilbert, 2008) and lacking of universality: the gradualist view that defines the origin of a human individual with the formation of the nervous system (at around either day 14 of gestation, or days 6-7 in the case of uterine implantation); and the view that considers fertilization (the fusion of sperm and oocyte membranes) as the beginning of a human life. Indeed, not all living creatures form a nervous system, become implanted in the uterus, or exist through fertilization (e.g. babies born following ICSI treatment never go through fertilization in the natural way, i.e. through the sperm and egg membranes fusion). The four-cell embryo occurs between the 40th and 50th hour of development in humans, so the doctor would have enough time to produce the number of embryos needed (e.g. consider the Italian law $n^{\circ} 40$ and similar) to perform pre-implantation diagnoses and the researchers could try to find new techniques to efficiently derive ES cells lines without having to enter into philosophical debates on the nature of existence (Devolder, 2009), or play semantic games on the meaning of the word embryo. In other words, we would like to offer a new suggestion (new functional copy) to widen the conceptual space of the present debate: we think that since the new functional copy 
of a genome is based on a scientific datum universally shared and identifiable in each living creature, vegetable and animal, naturally or artificially created, this scientific datum should deserve a great foundational value. We think that philosophers and ethicists should acknowledge that to know how a thing is (a factual biological datum that keeps invariably its intrinsic properties) influence both the deliberation about what should be done and the values attributed to the rules assumed by moral systems (rules can be differently valued depending on the circumstances in which they are asked to give behavioral answers). Even though we clearly cannot give a solution to the is/ought question, we hope to contribute to bridge it by stressing the is foundational merit.

\section{Stem cells from frozen embryos}

Human history highlights the many limits of knowledge-based societies, in particular, ideological preconceptions and prejudices. A perfect example of the impediment of the unreflective, easy route thinking is what political decision makers think about frozen embryos: they are considered "human beings" (whatever the stage of their development) and they can't be used for SC derivation. This has the dramatic result of a huge delay in possible therapeutic applications for Parkinson's, dystrophy and juvenile diabetes, just to name few examples. A recent clear cut example comes from the USA with the pro-life movements tangling the President Obama decision (Moreno, 2010).

As for the ethics of using frozen embryos for research, the supporters of the potentiality argument could accept the scientific evidence here exposed (clearly showing that the first expression of the functional genome occurs at the four-to-eight cell transition; McGaughey and Chang, 1969; Braude et al., 1988; Chen et al., 2010) without having to renounce any of their theoretical principles. Thus, the assertion of the functional genome would counter, for instance, the potentiality argument by opponents of human embryonic stem cell research and to deadlock the possibility to use frozen embryos for research. However it must be remembered that recent advancements in genetic reprogramming of somatic cell nuclei contributed by both Yamanaka's (Kyoto University) and Thomson's (Wisconsin University) teams (Yamanaka, 2009) are opening up new scenarios, even though certainly not in the short term, were the practical needs to use hES are likely to fade; or, in the best case scenario, we will be able to fully replace the use of hES with induced pluripotent stem cells (iPS). iPS are obtained thanks to the insertion of four genes responsible for stemness by retroviral transfection: Oct4, Sox2, c-myc, Klf4. The same four factors can be inserted into human cells using a true epigenetic virus-free transfection approach, DNA transposons (i.e., piggyBac, from the cabbage looper moth), thus avoiding the risk of insertional mutagenesis occurring with the use of retroviruses (Woltjen et al., 2009).

Stem cell technology challenges many of the principles of modern culture, such as progress, democracy and justice; it affects all aspects of our life and our health. Internationally, there is a clear absence of politico-cultural information able to pull out the points of contact between advances in scientific research and the autonomy of individuals over bio-existential choices. This absence is partly due to the fact that in recent years knowledge has progressed tumultuously. Even though there is little evidence (from empirical surveys and focus group studies) that the degree of public understanding of science has a linear relationship to the degree of acceptance/ rejection of techno-scientific developments (Wynne, 1995), we think that a better and widely diffused knowledge of the scientific data could ease the acceptance of, or at least smooth the opposition to human embryonic stem cell researche by showing how beneficial this research can be for human health.

However, in the field of biopolitics, the relationships between citizens and the state, as well as between democracy and rights, have not been redefined yet. The scientific community needs political decision makers to develop valid policy guidelines establishing the management of the wide-ranging issues generated by biotechnological revolution and stem cell research. The extreme importance and urgency of biotechnology research governance is a process that should be open to contribution by all citizens. If this were the case, they will have to expand their understanding of the intrinsic opportunities and limitations of biotechnology techniques and stem cell biology. Ideally, each individual should be able to constantly re-delineate the boundaries of his relationship with the world to stay abreast of the changes; each of us should re-consider the deeper meaning of life and its forms, using all the resources made available by our era's constant advances in knowledge: the biopolitics of the body and its transformations, birth, end-of-life decisions, biomedical experimentation and control of personal decisions, just to name a few. Only through the development of reflective attitudes will citizens be able to avoid the easy routes in the debate, e.g. the opinion that the research described here "will lead to technology taking control over humans".

\section{Scientific citizenship}

The organization of new knowledge and the development of new models of representation are the basis for a new and necessary form of democracy, in which new knowledge is not considered as a threat but as an opportunity. Instead of being considered a source of inequality, knowledge should actually serve to promote the welfare of all humanity, as Francis Bacon proposed four hundred years ago. To make this happen, the biosciences need to develop new analytical tools, both for the assessment of science-driven revolution and for the delivery of clear explanations to the general public, the lay-people; well-informed citizens can guarantee strong support for investments in scientific research, and can be able to develop independentopinions reflecting democratic decisions about what should or should not be done. A good example of procedural correctness can be found in the "White Paper on Genetics in the NHS" published during Tony Blair's government; this document is addressed to all citizens and establishes democratic monitoring ensuring respect for the elaboration of principles and ethical norms that permit multiple values. The biological knowledge available to us today puts many of the principles of modern culture to the test: freedom (e.g. the opportunities that genetic databanks offer medical research or criminal investigation), progress (opportunities in finance and in medical diagnosis), and even democracy and distributive justice; it is present in all areas of individual and social life. Biology's manipulation of living organisms (represented for example by the substantial opportunities offered by genetic modification (GM) technologies) has effectively brought about a scientific revolution which has almost exclusively been considered in terms of technological progress. Accordingly, the impact of such manipulation on modern culture has not been sufficiently discus- 
sed and assessed yet. This raises a philosophical and political question: should we refuse scientific progress or should we speed up the process of social awareness and management of the new relationship between science and society, instigated by the new biological revolution? The true nature of scientific endeavour is democracy: the advancement of scientific knowledge can mitigate or eliminate the inequalities that have historically characterized the life of all human beings. Developments in life sciences raise wideranging collateral issues (social, legal, political, economic, religious and philosophic), and the breadth of these issues is central to any analysis of the transformation for modern societies. Important are the role of politics and the extent to which the political system: (a) recognizes alternative policies as valid within a democratic framework and (b) invests in projects that promote shared values. Such values are an invaluable asset in a multicultural society, and science can contribute to their development. Citizens need to be scientifically literate and knowledgeable to live in a democratic society based on justice and equity. Only citizens with the conceptual tools to critically evaluate the new frontiers of scientific knowledge can ensure a democratic system; only in this way are they able to influence society in an effective way with their own independent opinions. This is a point that should be accepted by everyone as already proposed and published almost fifty-one years ago in "The two cultures"by Charles P. Snow (1960) and strengthened nowadays by the already welcome "The three cultures" (Kagan, 2009).

Political decision makers should work closely with scientists to ensure a fair and free diffusion of the scientific message for better informed citizens. The big question is how to achieve this goal, how to make citizens interested in scientific topics providing them sufficient information to make better decisions. We obviously think that the educational systems should devise programs useful to diffuse, pervasively, the relevance of science in present day societies. Scientific festivals, theatrical scientific plays, open-lab programs, science-and-the-city and science-rhymes performances (www.sciencerhymes.com.au/) should be opened to any community, including for example those that are usually not admitted (like inmates and convicts). This could enable a new concept of citizenship which goes beyond that of Jefferson's American Revolution, or of the French Revolution: in the era of globalization and scientific knowledge-based societies (knowledge has evidently become the real economic and social driving force), citizens will all have equal access to the biotechnological advancements and medical care they need, regardless of where they come from or how wealthy they are.

\section{Acknowledgements}

The authors wish to thank Prof. Giampaolo Azzoni (University of Pavia) and Prof. Carlos Valenzuela (University of Santiago de Chile) for their invaluable suggestions. Prof. Amedeo Santosuosso (Univ. of Pavia) and Dr. Francesca Cesari (stem cell editor for Nature) for their critical readings of the manuscript. We are greatly indebt to an anonymous referee for the time he spent on the first version of our manuscript and whose efforts let us to significantly improve it.

\section{References}

BRAUDE, P., BOLTON, V. and MOORE, S. (1988). First human gene expression occurs between the four to eight blastomers. Nature 332: 459-461.

CHEN, L., WANG, D., WU, Z., MA, L. and DALEY, G.Q. (2010). Molecular basis of the first cell fate determination in mouse embryogenesis. Cell Res 20: 982-993.

DEVOLDER, K. and HARRIS, J. (2005). Ambiguity of the embryo: ethical inconsist- ency in the human embryonic stem cell debate. Metaphilosophy 38: 153-169.

DEVOLDER, K. (2009). To be, or not to be? Are induced pluripotent stem cells potential babies, and does it matter? EMBO Rep 10: 1285-1287.

DOWNS, K.M. (2008). Embryological origins of the human individual. DNA Cell Biol 27: 3-7.

FINDLAY, J.K., GEAR, M.L., ILLINGWORTH, P.J., JUNK, S.M., KAY, G., MACKERRAS, A.H., POPE, A., ROTHENFLUH, H.S. and WILTON, L. (2007). Human embryo: A biological definition. Hum Reprod 22: 905-911.

FULKA, H., MRAZEK, M., TEPLA, O. and FULKA, J.R. (2004). DNA methylation pattern in human zygotes and developing embryos. Reproduction 128: 703-708.

GEORGE, R.P. and LEE, P. (2009). Embryonic human persons. EMBO Rep 10:301-306.

GIBSON, S. (2007). Uses of respect and uses of the human embryo. Bioethics 21:370-378.

GILBERT, S.F. (2008). When "Personhood" Begins in the Embryo: Avoiding a Syllabus of Errors. Birth Defects Res C 84: 164-173.

GREEN, R.M. (2008). Research with fetuses, embryos and stem cells. In The Oxford textbook of clinical research ethics. (Eds. E. Emanuel, C. Grady, R. Crouch, R. Lie, F. Miller and D. Wendler). Oxford University Press, Oxford, pp. 488-499.

JASANOFF, S. (2005). Designs on nature: Science and democracy in Europe and the United States. Princeton University Press.

KAGAN, J. (ED.) (2009). The three cultures: Natural sciences, social sciences and the humanities in the 21st Century. Cambridge University Press, Cambridge, UK.

MCGAUGHEY, R.W. and CHANG, M.C. (1969). Meiosis of mouse egg before and after sperm penetration. J Exp Zool 170, 397-410.

MAYER, W., NIVELEAU, A., WALTER, J., FUNDELE, R. and HAAF, T. (2000). Demethylation of the zygotic paternal genome. Nature 403: 501-502.

MORENO, J.D. (2010). Vanguard of the new biopolitics. Nature 467: 1031-1032.

MULKAY, M. (ED.) (1997). The embryo research debate. Science and the politics of reproduction. Cambridge University Press, Cambridge, UK.

PLACHTA, N., BOLLENBACH, T., PEASE, S., FRASER, S. and PANTAZIS, P. (2011) Oct4 kinetics predict cell lineage patterning in the early mammalian embryo. Nat Cell Biol 13:117-123.

PUSCHENDORF, M., TERRANOVA, R., BOUTSMA, E., MAO, X., ISONO, K., BRYKCZYNSKA, U., KOLB, C., OTTE, A.P., KOSEKI, H., ORKIN, S. H., VAN LOHUIZEN, M. and PETERS, A.H. (2008). PRC1 and Suv39h specify parental asymmetry at constitutive heterochromatin in early mouse embryos. Nat Genet 40: 411-420.

SAGAN, A. and SINGER, P. (2007). The moral status of stem cells. Metaphilosophy 38: 264-284.

SNOW, C.P. (ED.) (1960). The two cultures. Cambridge University Press, Cambridge, UK.

TESTA, G., BORGHESE, L., STEINBECK, J.A. and BRÜSTLE, O. (2007). Breakdown of the potentiality principle and its impact on global stem cell research. Cell Stem Cell 1: 153-156.

WYNNE, B. (1995). Public Understanding of Science. In Handbook of Science and Technology Studies (Eds. S. Jasanoff, G. E. Markle, J. C. Petersen and T. Pinch) Thousand Oaks, Sage Publications, California, pp.361-388.

WONG, C.C., LOEWKE, K.E., BOSSERT, N.L., BEHR, B., DE JONGE, C.J., BAER, T.M. and REIJO PERA, R.A. (2010). Non-invasive imaging of human embryos before embryonic genome activation predicts development to the blastocyst stage. Nat Biotech 28: 1115-1121.

WOLTJEN, K., MICHAEL, I.P. and MOHSENI, P. (2009). piggyBac transposition reprograms fibroblasts to induced pluripotent stem cells. Nature 458:766-770.

WOSSIDLO, M., NAKAMURA, T., LEPIKHOV, K., MARQUES, C.J., ZAKHARTCHENKO, V., BOIANI, M., ARAND, J., NAKANO, T., REIK, W. and WALTER, J. (2011). 5-Hydroxymethylcytosine in the mammalian zygote is linked with epigenetic reprogramming. Nat Comm 2:1-8.

YAMANAKA, S. (2009). Elite and stochastic models for induced pluripotent stem cell generation. Nature 460:49-52.

ZERNICKA-GOETZ, M., MORRIS, S.A. and BRUCE, A.W. (2009). Proclaiming fate in the early mouse embryo. Nat Cell Biol 13:112-114.

ZERNICKA-GOETZ, M. (2011). Making a firm decision: multifaced regulation of cell fate in the early mouse embryo. Nat Rev Genet 10:467-477.

ZIMMERMANN, J.W. and SCHULTZ, R.M. (1994). Analysis of gene expression in the preimplantation mouse embryo: use of mRNA differential display. Proc. Natl. Acad. Sci. USA 91:5456-5460. 


\section{Further Related Reading, published previously in the Int. J. Dev. Biol.}

Improvement of mouse cloning using nuclear transfer-derived embryonic stem cells and/or histone deacetylase inhibitor Sayaka Wakayama and Teruhiko Wakayama Int. J. Dev. Biol. (2010) 54: 1641-1648

Stem Cells in Biology and Disease - ESTOOLS International Symposium Sergio Pistoi

Int. J. Dev. Biol. (2010) 54: 1399-1404

Molecular tools, classic questions - an interview with Clifford Tabin

Michael K. Richardson

Int. J. Dev. Biol. (2009) 53: 725-731

Experimental embryology of mammals at the Jastrzebiec Institute of Genetics and Animal Breeding Jolanta Karasiewicz and Jacek Andrzej Modlinski

Int. J. Dev. Biol. (2008) 52: 157-161

History and status of embryology and developmental biology at Polish Medical Faculties and Schools Hieronim Bartel

Int. J. Dev. Biol. (2008) 52: 141-146

The morphogenesis of evolutionary developmental biology.

Scott F Gilbert

Int. J. Dev. Biol. (2003) 47: 467-477

From embryo to ethics: a career in science and social responsibility. An interview with Anne McLaren.

Brigid Hogan

Int. J. Dev. Biol. (2001) 45: 477-482

Germ cells and germ cell transplantation.

A McLaren

Int. J. Dev. Biol. (1998) 42: 855-860

Distribution of BDNF and trkB mRNA in the otic region of 3.5 and 4.5 day chick embryos as revealed with a combination of in situ hybridization and tract tracing.

F Hallböök and B Fritzsch

Int. J. Dev. Biol. (1997) 41: 725-732

5 yr ISI Impact Factor $(2009)=3.253$

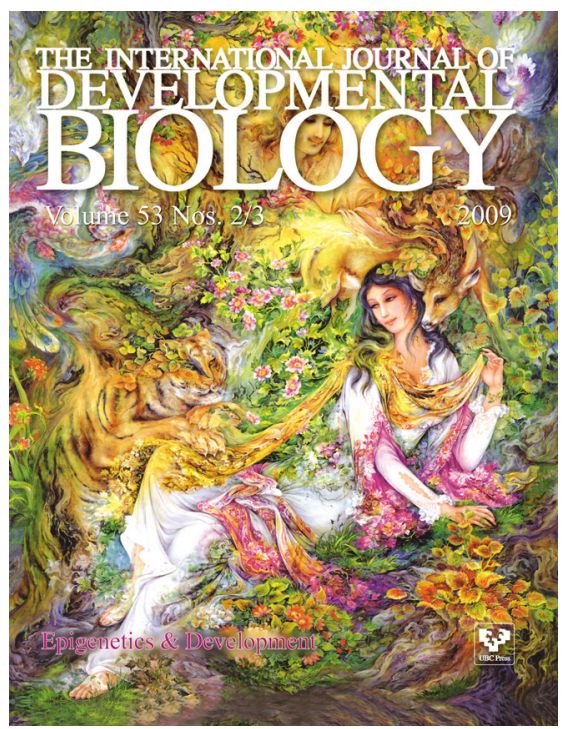

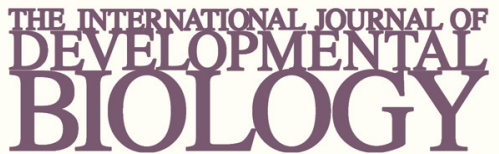

Volume 54 Nos. 6/7

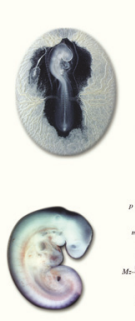

Developmental Hematopoiesis
Special Issue
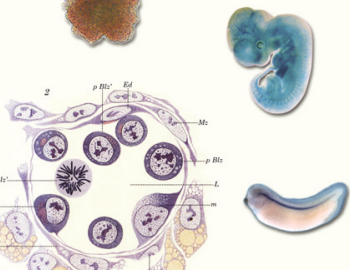

政

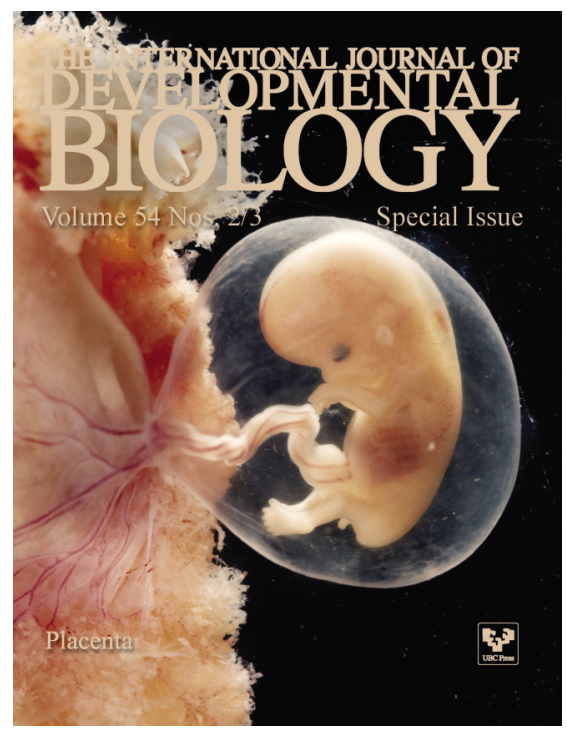

